\title{
Proceso de creación y de toma de decisión en los publicistas. El caso de la publicidad en Internet ${ }^{1}$
}

\section{Building process and decision-making by advertisers. The case of Internet advertising}

\author{
Marie-Pierre Fourquet-Courbet \\ Universidad de Avignon \\ marie-pierre.fourquet@univ-avignon.fr \\ Didier Courbet \\ Universidad de Niza-Sophia Antipolis \\ dcourbet@unice.fr
}

\begin{abstract}
Resumen
El artículo estudia los procesos sicológicos empleados por los publicistas para crear mensajes, apoyándose en una investigación exploratoria sobre 31 diseñadores de publicidad franceses. Muestra el rol primordial de sus teorías implícitas, fuertemente estructuradas, relacionado con la influencia individual de la publicidad. Los diseñadores proceden a una "disociación mental" paralelamente a actos sensorio-motrices gráficos, utilizando de manera interactiva, por una parte, procedimientos cognitivos inductivos, deductivos, analógicos y, por otra parte, tratamientos heurísticos y automáticos así como imágenes mentales. La creación se termina mediante una fase en que los publicistas a veces racionalizan, a posteriori, sus elecciones, principalmente de acuerdo con la voluntad del anunciador.
\end{abstract}

Palabras clave: Creación publicitaria, teorías implícitas, procesos de decisión, Internet, persuasión.

\footnotetext{
Abstract

The article studies the psychological process used by the publicists to create messages, supported on a exploratory research about 31 French publicity designers. It shows the primary role of their implicit theories, highly structured, related with the individual influence of advertising. The designers act in a "mental dissociation" parallel to graphics sensorymotor acts, using on one hand, cognitive inductions, deductive and analogical procedures, and on the other hand, heuristic and automatic treatments as well as mental images. The building ends in a phase where publicist sometimes rationalize, their elections a posteriori, mainly according to the announcer will.
}

1. Traducido desde el francés por Jacqueline Fernández Cellier. 
Keywords: Creating advertising, implicit theories, decision making, Internet, persuasion.

\section{Introducción}

A semejanza de la mayoría de los investigadores que se interesan en la comunicación mediática, consideramos esta última como un proceso constituido por tres polos en interacción, la producción, el dispositivo (del cual forma parte el discurso) y la recepción mediáticos, que se llevan a cabo en el seno de un conjunto de contextos (Charaudeau, 1997; Courbet y Fourquet, 2003a; Chabrol, Courbet y Fourquet-Courbet, 2004; Marchand, 2004; Lochard y Soulages, 1998). Aun cuando, en general, conviene considerar sistemáticamente estos tres polos en conjunto, existe un interés epistemológico cierto que hay que concebir y validar de los modelos localmente, estudiando más específicamente las dos díadas que articulan "producción-dispositivo mediáticos" y “dispositivo-recepción mediáticos". Si bien a menudo trabajamos sobre este último tipo de articulación (Courbet y Fourquet, 2003b; FourquetCourbet y Courbet, 2004), esta investigación se refiere a la interacción producción-dispositivo en un contexto de comunicación publicitaria en Internet. A pesar de la abundante literatura dedicada a la publicidad, pocas investigaciones científicas han estudiado la manera en que los mensajes nacen en el espíritu de los diseñadores publicitarios. El objetivo es, por una parte, comprender mejor cómo opera el proceso psicológico en el cual se basa la creación de los mensajes publicitarios y, por otra parte, analizar los mecanismos de decisión, pero también los saberes y saber-hacer utilizados, gracias a una investigación cualitativa sobre 31 diseñadores de e-publicidad. Se trata principalmente de estudiar las eventuales representaciones sociales y teorías implícitas compartidas por los diseñadores publicitarios y saber cómo se movilizan en el proceso de la creación.

Partiendo del principio que toda investigación en comunicación mediática debe precisar el marco conceptual utilizado, principalmente para definir la producción y el dispositivo mediáticos, comenzamos por determinar algunos elementos relacionados con el contexto teórico comunicacional. Luego construimos un marco conceptual más específico que une psicología social y etnometodología con el fin de conocer mejor el proceso de producción de los dispositivos publicitarios. Después de haber precisado los objetivos detallados y el método de investigación, indicamos y discutimos los resultados, los límites, así como las nuevas perspectivas que abre esta investigación cualitativa.

\section{Contexto teórico y objetivos de la investigación}

Después de los trabajos de Lochard y Soulages (1998) consideramos el concepto de dispositivo, en un sentido restringido, como un conjunto estructurado de medios lingüísticos, pluri-semióticos, aplicados por una instancia de producción para realizar una intención comunicativa. Localmente, el dispositivo comunicacional es presa de procesos conjuntos de particularización que resultan de la intervención de cinco tipos de factores (Lochard, 1999): 
factores técnicos, factores socio-organizacionales relacionados con la génesis y la evolución de las organizaciones mediáticas que están en su origen, factores socio-profesionales relacionados con los modos de organización de las empresas concernidas, factores culturales que integran las formas de interacciones humanas de las cuales la producción mediática es el teatro, factores representacionales donde las instancias de producción buscan construir, en función del imaginario socio-discursivo supuesto compartido por el público, efectos de empatía sobre la base de mecanismos de reconocimiento.

Nuestra investigación se referirá más específicamente al medio Internet. Estudiar las interacciones producción-dispositivo publicitario en Internet a la luz de la psicología social y la etnometodología conduce a poner en evidencia el hecho que el acto de comunicación mediático es concebido por y para un sujeto social.

Para explicar los procesos psicológicos que emplean los publicistas al momento de la creación de los banners publicitarios se requiere estudiar, primeramente, las representaciones socio-cognitivas que tienen en común. Las representaciones sociales, como sistemas sociocognitivos, son formas de conocimientos corrientes, llamados “de sentido común", socialmente elaborados y compartidos por un grupo de individuos. Para las personas, tienen una intención práctica de organización del entorno y de orientación de las conductas (Moscovici, 1984). También nos interesamos en un tipo particular de representaciones: las teorías implícitas. Estas son teorías sin fundamento científico, a las cuales los actores sociales han recurrido para explicar la realidad social. Ellas son llamadas "implícitas" ya que las personas que las emplean no están necesariamente conscientes de ello y no siempre saben explicarlas de manera precisa (Furnham, 1990; Kover, 1995).

En las investigaciones sobre los procesos de decisión de los actores organizacionales en situación de trabajo, los psicólogos sociales cognitivos han puesto en evidencia procesos reiterativos y complejos que relacionan dos etapas. La primera etapa es la de la movilización de los saberes y saber-hacer almacenados en memoria declarativa o procedural para realizar una acción profesional. Los procedimientos cognitivos que permiten aplicar a una situación particular conocimientos ya almacenados en memoria son deductivos y "descendentes" (top down). La segunda etapa es la de la adquisición por y en la acción de nuevos saberes y habilidades. Estos procedimientos cognitivos, inductivos, son calificados como "ascendentes" (bottom-up). Ellos contribuyen a formarlo que los profesionalesllaman "la experiencia" (Schön, 1994). En ambos casos, los psicólogos sociales cognitivos han mostrado la utilización frecuente de heurísticas entre los responsables de empresa, es decir la utilización de reglas de decisión simples, fáciles de aplicar y mucho más útiles funcionalmente que válidas científicamente. ¿Qué pasa en el campo de la publicidad? El primer objetivo de esta investigación es estudiar los saberes, representaciones sociales, teorías implícitas y saber-hacer que los diseñadores de banners tienen en común. ¿Cuáles son sus contenidos? ¿Cómo se utilizan? ¿Cómo los publicistas los articulan con informaciones provenientes de la situación particular en la cual trabajan? 
Los modelos más adecuados para explicar los aspectos dinámicos de los tratamientos de informaciones en la toma de decisión de los diseñadores publicitarios, se encuentran en las teorías de gestión sobre la toma de decisión en empresas. En el seno de este campo de investigación, utilizamos tres tipos de modelos: los modelos clásicos dela decisión, los modelos psicológicos (o de conducta) de la decisión y de la creatividad. Los integramos con el fin de analizar el diseño de los mensajes publicitarios. Los modelos clásicos plantean que, frente a una decisión, el profesional sigue un proceso serial: define claramente el problema, atribuye prioridades a los objetivos, analiza todos los medios y acciones posibles y sus consecuencias, luego elige la mejor de las soluciones posibles para cumplir los objetivos (De Young, 2002). Los modelos psicológicos de la decisión insisten en el hecho que los responsables, actuando dentro de un contexto de incertidumbre (donde los fenómenos, determinados por múltiples factores, son poco previsibles) están limitados cognitivamente y obligados por el tiempo. Tienen una racionalidad limitada y toman decisiones según representaciones que se hacen de una situación. Los actores organizacionales, de acuerdo al principio del "enfoque satisfactorio de la decisión" (vid. Augier, 2001; Forest y Mehier, 2001; Hvide, 2002) elegirían, a menudo, la primera solución que les parece dar un resultado satisfactorio o aceptable a los problemas.

El segundo objetivo de la investigación es explicar cómo operan el proceso y el tratamiento de las informaciones durante la concepción publicitaria en Internet. ¿Cómo se inicia el proceso? ¿Cómo son tratadas las informaciones en memoria de trabajo? ¿Cuándo y por qué el publicista decide detener el proceso de creación? Se trata también de contribuir a explicar la manera en que saberes, representaciones y competencias, son integrados al proceso de diseño.

Sin embargo, el conocimiento del proceso de diseño no sería completo si no estudiamos el sentido que los profesionales dan a sus acciones. La etnometodología nos incita a diferenciar bien el acto de producción de la publicidad del acto de enunciación mediante el cual los profesionales describen verbalmente sus prácticas. Partiendo del principio que el "sentido de la acción, es decir su carácter descriptible, verbalizable e inteligible, se encarna en la acción” (Garfinkel, 1967), para la etnometodología no hay sentido en sí mismo, independiente de la acción que lo encarna. Así, por la misma razón que no existe inteligibilidad de la acción sin la acción de diseño publicitario propiamente tal, no existe inteligibilidad si dejamos de lado a los sujetos sociales que la producen y analizan. El tercer objeto de la encuesta es estudiar, a través de tres características del acto de enunciación, la forma en que los diseñadores hablan de sus prácticas y los métodos que utilizan para poder verbalizar sus saberes y saber-hacer movilizados (Livington, 1987).

La primera característica del acto de enunciación es la descriptibilidad (accountability). Relatar la producción y el diseño de un mensaje publicitario y hacer el mensaje publicitario propiamente tal son dos formas de producir un account del objeto "publicidad". El account es un "producto" o una "representación" verbal o imaginada de una actividad productora de sentido. Producir un discurso sobre una práctica finalizada requiere descriptibilidad de parte del 
publicista, es decir una aptitud para describir la situación con cierta perspectiva. Por lo tanto, se tratará de analizar la descriptibilidad de los publicistas en Internet.

La segunda característica es la reflexibilidad (Garfinkel, 1967) de los publicistas: se trata de su aptitud para analizar verbalmente sus saberes y saber-hacer empleados para realizar acciones. ¿La reflexibilidad publicitaria está constituida por meta-conocimientos, por un saber decir y un saber verbalizar, asociados al comportamiento de creación de los mensajes? ¿Cómo hablan los diseñadores de los saberes que utilizan? ¿Qué aptitud tienen para analizar sus presuposiciones, sus convicciones, sus dudas, su saber-hacer, etc. y cómo lo hacen?

La tercera característica del acto de enunciación es la indexicalidad (Garfinkel y Sacks, 1970) que empleamos en un sentido particular. El publicista moviliza conocimientos que va a aplicar diferentemente según el contexto y la situación (requerimientos del anunciador, obligaciones provenientes de la competencia, etc.). Evaluando la indexicalidad, analizamos principalmente la capacidad de los publicistas de aplicar, en un contexto particular, las informaciones que han almacenado en memoria. Estudiamos además los procesos que utilizan para poner en contexto sus conocimientos.

Convocando de forma interdependiente y complementaria estos tres conceptos etnometodológicos, se trata de evaluar el grado de conciencia que los diseñadores tienen de su capacidad para verbalizar (a) el saber y saber-hacer a los que recurren, (b) las informaciones que tratan y $(\mathrm{c})$ los procedimientos que siguen en el acto de creación. ¿Con qué grado de precisión llegan a verbalizar los conocimientos y procedimientos que utilizan?

\section{Método}

El método cualitativo y hermenéutico es el más apropiado para alcanzar estos objetivos exploratorios. Hemos consultado a 31 diseñadores de publicidad de la Internet francesa, seleccionados con el fin de constituir una muestra diversificada principalmente según los siguientes criterios: Actividad de la organización a la cual pertenece el diseñador consultado (agencia de publicidad, agencia especializada en Internet, diseñador free-lance), tamaño de la organización (estructura pequeña, mediana y grande), sector geográfico (provincia, región parisina). Los sujetos tienen perfiles variados en cuanto a la edad y al nivel de estudios (hemos encuestado tanto a autodidactas como a individuos que tienen un diploma de enseñanza superior en infografía y en publicidad). Los sujetos fueron consultados cara a cara mediante entrevistas semi-dirigidas gracias a una pauta de entrevista en la cual aparecen preguntas muy abiertas. En cada entrevista había siempre una parte en que solicitábamos a los publicistas ilustrar su discurso mediante demostraciones en el computador.

Los discursos recolectados (1203 intervenciones y 56780 palabras) fueron tratados mediante análisis de contenidos temáticos detallados. Las intervenciones fueron repartidas en diferentes categorías exclusivas que representan temas y subtemas. Por un lado, hemos evaluado la parte relativa de cada tema (se identificaron 13 temas) y sub-tema en relación con el conjunto del corpus tratado y, por otro lado, la parte de cada sub-tema en relación con el tema al cual 
está vinculado. Las fidelidades intra-codificador e inter-codificadores (dos codificadores) del análisis son satisfactorias para una investigación exploratoria.

\section{Resultados y discusión}

\subsection{La fase de creación en memoria de trabajo: interacciones virtuales y saber-hacer automáticos}

Los resultados muestran que el diseñador escucha “voces intrapsíquicas” que representan seis actores del proceso de producción publicitaria y que los hace dialogar en memoria de trabajo. El conjunto de estos procesos de interacción imaginarios está dirigido por una voz que es la del yo creativo durante la creación. Cuando el yo del diseñador interactúa intrapsíquicamente con estos "otros internalizados", se puede hablar de una "disociación psíquica", incluso de un "trance creativo". Nuestros resultados corroboran y completan así los de Kover (1995), que describe el acto de creación publicitaria como un diálogo interno cercano a la "locura" o a la "escritura automática”.

La primera voz que escucha el creativo es la del internauta-receptor que reacciona al mensaje creado. Si el creativo conoce bien el producto publicitado, se toma como referente. Entonces disocia su yo de manera dual y dialoga con otro yo que se convierte en el receptor típico del banner. Si conoce poco el producto, hace hablar a un receptor que él construye a partir de las representaciones mentales típicas que posee sobre el individuo.

La segunda voz es la del anunciador. El publicista imagina lo que este último diría frente al banner diseñado. Las representaciones empleadas fueron construidas esencialmente a partir de las informaciones entregadas por el anunciador, ya sea que figuren o no en las bases.

El yo de los sujetos consultados interactúa también con dos colegas imaginarios. El primero encarna a un excelente diseñador de banner. El segundo conoce perfectamente las últimas modas y tendencias recientes en el campo de la creación publicitaria en Internet. Estos dos colegas son construidos mentalmente a partir de una revisión permanente que realiza el creativo en la web, buscando así "impregnarse” con las últimas modas vía las prácticas de los otros diseñadores. En su gestión de diseño, el yo del creativo dialoga con ellos para evaluar, por una parte, la estética de su trabajo en relación con las tendencias actuales y, por otra parte, para evaluar el valor de sus elecciones en relación con las de los colegas y por lo tanto, indirectamente, en relación con las normas y prácticas de la profesión.

La quinta voz encarna la experiencia del publicista propiamente tal. Los mecanismos cognitivos que apoyan el diseño de un banner mediante lo que los publicistas llaman "su experiencia”, son poco reflexivos. Los diseñadores hacen poca diferencia entre dos diseños "por experiencia” " “por intuición”. Cuando se les pide explicar más detalladamente cómo interviene su experiencia en el proceso de creación, proceden por un mecanismo de inferencia negativa. El proceso de auto-observación que espontáneamente emplean durante su práctica habitual no 
logra ni poner en palabras las reglas que utilizan, ni detallar sus tratamientos. Por consiguiente, es altamente probable que los tratamientos se basen en saberes-hacer procedurales automáticos (Barbier, 1996), es decir, poner en práctica sin conciencia, sin carga mental y sin control intencional (Kirsner et al., 1998). Con la repetición y una gran frecuencia de uso, las heurísticas y los procedimientos se automatizan y se vuelvan "hábitos" de creación, difíciles de explicar por su carácter fuertemente automático. Este desconocimiento de sus propios razonamientos no es despreciado sino, al contrario, aparece, ante sus ojos, como un valor, una especie de genio y de talento artístico. Perteneciendo a su propia identidad y a su yo, este talento es muy valorado en perjuicio de los saberes científicos o de los saberes provenientes de la universidad.

Durante o inmediatamente después de las interacciones verbales intrapsíquicas, viene una fase de materialización cuya principal característica es ser del tipo ensayo-error. Basándose en un principio de diseño por tentativa, este mecanismo está constituido por varias etapas que se realizan, ya sea sobre papel con lápiz, ya sea por imaginería mental. Gracias a un proceso cognitivo o sensorio-motriz espontáneo y muy rápido, los diseñadores producen su mensaje según tres estilos. Algunos representan la creación prioritariamente por imaginería mental. Otros prefieren efectuar ante todo un acto de producción sensorio-motriz utilizando, lápiz en mano, un saber-hacer procedural gráfico. Finalmente, otros, utilizan los dos de manera reiterada. La producción que resulta sólo se evalúa una vez que es visualizada o realizada gráficamente.

\subsection{Los procesos elementales y las teorías implícitas en la creación}

Un análisis de la naturaleza del proceso de creación de los banners dirigido por voces intrapsíquicas muestra que está compuesta por cuatro tipos de procesos latentes (quellamamos procesos elementales) que se desarrollan de manera reiterada e interactiva. Para facilitar la comprensión primero presentamos el primer proceso solo, luego los otros tres en conjunto.

3.2.1. Un proceso deductivo a partir de las teorías implíitas. El primer proceso elemental es un proceso deductivo donde el publicista aplica, a la situación de creación particular, representaciones cognitivas y teorías implícitas almacenadas en la memoria. De forma general, el contenido de las teorías implícitas tiene un carácter universal. Los publicistas generalizan y no prevén ninguna excepción: estiman que estas teorías son válidas cualquiera sea la situación, los anunciadores y el público objetivo. Los saberes empleados son esencialmente enunciados respecto de relaciones causales. Estas asocian sistemáticamente procedimientos y sistemas estético-semióticos, permitidos técnicamente por Internet, a los efectos que estos últimos producen en el internauta en recepción (e.g. "el centelleo llama la atención del receptor"). Los profesionales han sido capaces de explicar y verbalizar en forma relativamente fácil las teorías implícitas que contribuyen, mediante un proceso descendente (top down), a tomar decisiones referentes a procedimientos semióticos y estéticos a utilizar en casos particulares. También, el proceso cognitivo deductivo es muy reflexivo. ¿Los publicistas entrevistados poseen teorías implícitas idénticas? Los resultados muestran que las teorías implícitas tienen en común varios 
grandes conjuntos de representaciones. Estos orientan la concepción del sistema estéticosemiótico en cada etapa del proceso de creación.

Una gran influencia serial de los procedimientos estético-semióticos. Los diseñadores disponen de dos grandes tipos de teorías implícitas sobre la influencia de la e-publicidad y sobre el internauta. Algunos diseñadores piensan que Internet tiene tanto o más influencia que los medios publicitarios clásicos (televisión, prensa) y esto, sobre todo cuando su contenido está específicamente adaptado al perfil psicológico y socio-demográfico de las personas destinatarias. Otros publicistas, al contrario, estiman que su influencia es baja. El internauta sería cognitivamente más "activo" que el receptor de los medios tradicionales y mucho más capaz de evadir la publicidad. Esta evasión se refiere sobre todo a las publicidades intrusivas (pop-up) que serían nefastas para el anunciador. En efecto, ellas interfieren en la navegación del internauta quien trata conscientemente de evitarlas. Por otro lado, el receptor que adquiere experiencia se habría habituado a la e-publicidad, cuya influencia habría desde entonces disminuido. Los resultados muestran que los actores entrevistados valorizan mucho el poder de influencia de su creación, guardando silencio respecto del rol de los otros factores que intervienen en la producción de las campañas publicitarias, también susceptibles de influir en los receptores (e.g. lo que los profesionales llaman el "posicionamiento marketing", la repetición de los mensajes, el plan de medios, etc.). A condición que se adapten bien al perfil sociodemográfico y psicológico del público objetivo, los diferentes procedimientos que componen un mensaje, tendrían la capacidad de orientar e influir en los tratamientos psicológicos de todos los internautas y de hacerlos cliquear sobre el banner. Además, el poder de influencia de los únicos sistemas estético-semióticos creados por los creativos sería lo suficientemente poderoso para modificar los comportamientos de los consumidores.

En las teorías implícitas, el proceso de influencia es serial en la medida que se desarrolla en cuatro etapas que se suceden en el tiempo, debiendo pasarse cada una de ellas para poder acceder a la siguiente. Las teorías implícitas contienen representaciones precisas de los procedimientos capaces de hacer pasar al internauta por estas cuatro etapas. Cada procedimiento está sistemáticamente asociado a uno o varios efectos psicológicos específicos y relativamente "potentes", cualesquiera sean las condiciones de recepción y los internautas.

Así, para pasar la primera etapa, es decir llamar la atención del internauta, el publicista utiliza esencialmente:

- procedimientos formales: animaciones y movimientos en los banners, creados por cambios formales (e.g. transformación de logo), gifs animados, desplazamientos de texto, centelleos, contrastes movimiento/fijo, contrastes de color;

- procedimientos semánticos: utilización de palabras particulares ("promoción”), creación de una ruptura semántica en el banner, foto difícilmente interpretable semánticamente, creación lúdica; 
- la originalidad del texto y de la imagen que puede llegar a choquear al internauta (por la atmósfera gráfica, una foto particular, la utilización de códigos desplazados en relación con el universo semántico del producto).

Sólo una vez que el receptor ha prestado atención, puede pasar a la segunda etapa donde podrá comprender el contenido. Para pasar con éxito esta etapa, el mensaje debe ser simple en el plano formal y explícito en el plano semántico (coherencia entre el texto y las imágenes). A pesar del alto grado de iconicidad de la publicidad en Internet, la comprensión sería esencialmente generada por el texto.

Una vez que ha comprendido, el internauta pasa a la tercera etapa: la memorización del mensaje. Se utilizan dos procedimientos principales para favorecer el paso de esta etapa:

- hacer resaltar inmediatamente los elementos que se destacan del mensaje, ya se trate del atributo semántico principal o de "visuales potentes" (colores que se memorizan bien, "desplazamiento visual", imagen divertida).

- la repetición de los elementos primordiales en el mismo banner o en banners diferentes. Sin embargo, habría un umbral máximo de repetición que no se debe sobrepasar para no interferir en la navegación y provocar el rechazo psicológico de la marca. Ninguno de los publicistas consultados pudo cuantificar este umbral.

Para incitar a cliquear sobre el banner (cuarta etapa), hay que llamar la atención del internauta intrigándolo (con una oferta comercial sorprendente o imágenes shocks), utilizando un juego o seduciéndolo mediante un beneficio. El diseñador se fija también en que el mensaje inspire confianza. Incluso si técnicas específicas incitan al clic (animaciones, colores vivos), es toda la creación (su simplicidad, su originalidad) la que influye en el comportamiento del internauta.

Una relación casi interpersonal con el internauta. Internet es percibido como un medio más interactivo y más rápido que los medios de masa llamados tradicionales. La interactividad está asociada, primeramente, a la buena capacidad de "seleccionar el grupo objetivo" (ciblage) de Internet y, segundo, a las posibilidades de reacción de la pareja productor-internauta. En su creación, los diseñadores adaptan entonces los mensajes a los perfiles psicológicos y sociodemográficos en forma precisa y practican una "comunicación muy personalizada". Ellos eligen también cuidadosamente la página de inicio, reforzando así la impresión de relación interpersonal privilegiada entre el anunciador y el receptor. La personalización permite además, insertarse en la corriente actual de la comunicación comercial: el Consumer Relationship Management. Gracias a al feedback que ofrece Internet (vía la tasa de clicks o la cantidad de productos vendidos por e-compra), el diseñador puede evaluar rápidamente la calidad de los banners creados y modificarlos en consecuencia.

3.2.2. Proceso inductivo, mediante heurísticas y analógico. El segundo proceso elemental es un proceso donde el publicista analiza ante todo las informaciones que provienen de la situación y de casos particulares: anunciador, perfil de los internautas, página de inicio, etc. Si bien están conscientes de las informaciones fundamentales a partir de las cuales producirán 
sus mensajes, los profesionales consultados manifestaron dificultades para verbalizar los tratamientos que emplean en la toma de decisiones. Esencialmente ascendente (bottom up), el proceso elemental inductivo, basado en el contexto específico y los datos, utiliza saberes mayoritariamente operativos y, en menor parte, afirmativos. Los enunciados de tipo operativo, es decir que explican los saberes-hacer cognitivos en la producción, son poco reflexivos. Para que los actores expliciten los procesos inductivos, deben realizar un proceso suplementario de reflexividad, de toma de conciencia y de puesta en palabras. Con el fin de ser verbalizados, estos saberes-hacer cognitivos deben también estar asociados a un "saber-decir". Sólo una minoría de los publicistas consultados da cuenta espontáneamente de esto en forma detallada.

El tercer proceso elemental utiliza heurísticas de accesibilidad mental y de representatividad. De manera más o menos consciente, el uso de heurísticas de accesibilidad mental consiste en recurrir a procedimientos estético-semióticos que son los más accesibles mentalmente. Cuando el publicista tiene conciencia de recurrir a este principio, lo justifica, primeramente, por el hecho de que este modo de producción constituye su "estilo de creación". En este caso, los saberes y saber-hacer, son rutinarios y corresponden a verdaderos hábitos de creación. Segundo, el creativo se justifica explicando que el procedimiento es particularmente eficaz y que este último tiene un impacto pertinente en el internauta. En este segundo caso, la heurística empleada se parece a la heurística de representatividad. Entonces, el actor recurre a procedimientos, según un razonamiento extremadamente simple, ya sea porque serían, en las teorías implícitas de los productores, los más eficaces, ya sea porque, por la moda, corresponden a la tendencia del momento en el medio Internet o en publicidad.

Muy reflexivo, el cuarto proceso elemental es un mecanismo analógico. Los análisis de contenido de las entrevistas ponen en evidencia dos tipos de procesos analógicos. El primer tipo de analogía consiste en inspirarse en los banners publicitarios creados por otros diseñadores en Internet, es decir en el mismo medio de comunicación (analogía intramedio). El segundo tipo de analogía, intermedio, consiste en transferir procedimientos estéticos y semióticos, habitualmente o recientemente utilizados ya sea en otros medios de comunicación (publicidad o patrocinio televisivo) o en otros géneros del medio informático (sitio Internet, CD Rom, etc.).

\subsection{Proceso de auto-evaluación y proceso de decisión de detención de la creación}

Los resultados de la investigación muestran que con el fin de autoevaluar la calidad de su creación, los publicistas forman lo que llamamos, en referencia a Weber (1995), un "banner ideal-típico”. El creativo sólo detendrá su proceso de diseño cuando estime que su creación está lo suficientemente cerca de su tipo-ideal. Los publicistas tratan de conocer los criterios explícitos e implícitos que utilizará el anunciador para evaluar los banners que hayan creado. El objeto es entonces, por una parte, crear un banner ideal-típico que responda a estos criterios y, por otra parte, incorporar estos últimos en su argumento de presentación del mensaje terminado para el anunciador. El creativo desea sistemáticamente, durante o después del diseño 
del banner, justificar su elección estética y semiótica compartiendo los criterios de evaluación y de aceptación del anunciador. Si él desconoce sus criterios, construye una representación según su experiencia previa y representaciones que se hace de su cliente.

Durante la creación, el diseñador evalúa sistemáticamente un primer criterio: el carácter estético de su mensaje. Los diseñadores insisten en el carácter rápido, no intelectualizado y no elaborado de este tipo de evaluación: el mensaje debe gustar inmediatamente. Cuando el proceso de diseño que utiliza es muy reflexivo y verbalizable, principalmente cuando utiliza un mecanismo de deducción, el diseñador estima que sus decisiones son racionales a priori. Cuando el acto de diseño está dominado por un comportamiento sensorio-motor (dibujar manualmente) y, por lo tanto, cuando el proceso de diseño es poco reflexivo, el diseñador justifica muy a menudo su producción a posteriori. En cada avance significativo de la creación, el creativo realiza una puesta en palabras y una verbalización. Sistemáticamente y en directo, produce, por una parte, un nuevo significado del mensaje en su conjunto y, por otra parte, diferentes procedimientos estéticos y semióticos que lo constituyen. El diseñador alterna entonces de manera muy rápida fases sensorio-motrices de diseño y fases de auto-observación. Al contrario de lo que indican la mayoría de los trabajos científicos sobre el proceso de creatividad (Kabanoff y Rossiter, 1994), nuestros resultados ponen en evidencia el hecho de que el proceso de evaluación no termina el acto de creación pero es iterativo: el creativo autoevalúa reiteradamente su mensaje, incluso durante la realización. Por una parte, busca justificar de manera racional los sistemas estéticos y semióticos que ha diseñado utilizando los criterios de evaluación de los anunciadores, y por otra parte, comparar el mensaje en vías de constitución con su mensaje "tipo-ideal".

Muy a menudo, el proceso de creación del mensaje finaliza cuando el banner responde a los criterios de aceptación del cliente tal como el creativo se los representa. El concepto de racionalidad limitada de Simon (1960) se aplica entonces a la producción publicitaria y en particular al proceso de decisión de detención. El diseñador no busca diseñar siempre los mensajes más influyentes, sino crear mensajes cuya justificación pueda ser aceptada por el anunciador. En este caso, este enfoque satisfactorio de la producción requiere una justificación del proceso de diseño a posteriori. El objetivo es dar al mensaje la apariencia de racionalidad y principalmente de conformidad a las reglas de creación publicitaria clásicamente utilizadas en la profesión. El argumento que el publicista va a desarrollar frente al anunciador para "vender" su banner debe ser percibido como suficientemente persuasivo para hacer creer al anunciador que el banner efectivamente logrará sus objetivos.

\section{Conclusión, límites y nuevas perspectivas de investigaciones}

Aun cuando en esta investigación cualitativa no se pretende la representatividad de la población, sería conveniente concebir una investigación cuantitativa para aumentar la validez de los resultados, principalmente aquellos relacionados con las teorías implícitas de la influencia de la e-publicidad. Por otra parte, existiría un real interés en ampliar la diversidad de la muestra 
realizando un estudio comparativo internacional y encuestando a diseñadores de e-publicidad provenientes de otros países además de Francia. Por otra parte, sería interesante estudiar las teorías implícitas según la profesión de base o la formación inicial del diseñador en Internet: hemos observado, en efecto, diferentes formas de concebir el modo de influencia psicológica de Internet según si el entrevistado es infografista, informático o publicista de formación. También sería pertinente estudiar, en el mismo contexto teórico, los procesos de creación en los medios más tradicionales, principalmente con el fin de conocer mejor las teorías implícitas utilizadas por la publicidad televisiva, la prensa... y compararlas con las utilizadas por la e-publicidad.

Otra perspectiva interesante consistiría en confrontar las teorías implícitas de la influencia de la publicidad, tal como existen entre los diseñadores, con los resultados de las recientes investigaciones científicas sobre la influencia de Internet, con el fin de evaluar la validez psicológica de las teorías implícitas de los profesionales. Además de un interés teórico, los profesionales encontrarían ahí un interés operacional en la medida que tal investigación podría contribuir a corregir algunas desviaciones que se han puesto aquí en evidencia. Un primer estudio de esta naturaleza (Fourquet-Courbet, 2004) ya resaltó que los publicistas tenían la tendencia a sobrevalorar la actividad cognitiva del internauta; efectivamente, recientes investigaciones científicas han demostrado que ciertas publicidades en Internet no tienen necesidad de ser memorizadas por el internauta, ya que tienen influencia implícita en su actitud (Courbet, 2004).

\section{Referencias bibliográficas}

Augier, M. (2001, jun). «Subline Simon: The consistent vision of Economic Psychology's Nobel Laureate». Journal of Economic Psychology. No 3. Vol. 22, pp. 307-334.

Barbier, J.-M., dir. (1996). Savoirs théoriques et savoirs d'action. París: Presses Universitaires de France.

Charaudeau, P. (1997). Le discours d'information médiatique. París: INA-Nathan.

Chabrol, C.; Courbet, D. y Fourquet-Courbet, M.-P. (2004). «Psychologie sociale, traitements et effets des medias». Questions de Communication. No 5, pp. 5-18.

Courbet, D. y Fourquet, M. P., dir. (2003a). La Télévision et ses Influences. De Boeck Université. coll. Médias Recherche: INA.

(2003b). «Réception des images d'une catastrophe en direct à la télévision. Etude qualitative des réactions provoquées par les attentats du 11 septembre 2001 aux Etats-Unis au travers du rappel de téléspectateurs français ». Revue Européenne de Psychologie Appliquée. № 1. Vol. 53, pp. 21-41

(2004, sep.). «Nouvelle méthode d'étude des cognitions en réception (ECER) et application expérimentale à la communication politique». Revue Internationale de Psychologie Sociale. No 3 . Vol. 17.

De Young, R. (2002, mar.). «Practical-Theoretical Approach in the application of Theory Models of Organizational Behavior». Journal of American Academy of Business, pp. 361-364. 
Forest J. y Mehier, C. (2001, sep.). «John R. Commons and Herbert A. Simon on the Concept of Rationality». Journal of economic Issues, pp. 591-605.

Fourquet-Courbet, M. P. (2004). «Influence attendue et influence effective de la publicité sur Internet. Des représentations sociales des producteurs aux modèles scientifiques». Questions de Communication. No 5, pp. 31-53.

Furnham, A. (1990). «Commonsense Theories of Personality». En: Everyday Understanding: Social and Scientific implication. London: Sage, pp. 176-203.

Garfinkel, H. (1967). Studies in Ethnomethodology. New York: Prentice Hall.

Garfinkel, H. y Sacks, H. (1970). «On formal Structure of Practical Actions». En: Theoretical Sociology. London: Sage, pp. 176-203.

Hvide, H.K. (2002, may.). «Pragmatic Beliefs and Overconfidence». Journal of Economic Behavior and Organisation. No 1. Vol. 48, pp. 15-28.

Kabanoff, B. y Rossiter, J. R. (1994). «Recent Developments in Applied Creativity». International Review of Industrial and Organizational Psychology. No 9, pp. 283-324.

Kirsner, K. et al., eds. (1998). Implicit and explicit Mental Processes. New Jersey: Lawrence Erlbaum Assoc.

Kover, A. J. (1995). «Copywriters' Implicit Theories of Communication: An exploration». Journal of Consumer Research. № 4. Vol. 21, pp. 596-611.

Livingston, E. (1987). Making Sense of Ethnomethodology. London and New York: Routledge and Kegan Paul.

Lochard, G. (1999). «La notion de dispositif dans des études télévisuelles: logique et trajectoire d'emploi». Hermès. № 25.

Lochard, G. y Soulages, J.-C. (1998). La communication télévisuelle. Paris: Armand Colin.

Marchand, P. (2004). Psychologie sociale des medias. Presses Universitaires de Rennes.

Moscovici, S. (1984). Psychologie Sociale. París: Presses Universitaire de France

Schön, D. A. (1994). Le praticien réflexif. A la recherche du savoir caché dans l'agir professionnel. Montréal: Editions Logiques.

Simon, H. (1960). The New Sciences of Management Decision. New York: Harper and Row.

Weber, M. (1995). Economie et Société. París: Plon. 